\title{
Organizational Citizenship Behavior (OCB): Efek Budaya Organisasi dan Work-Family Conflict
}

\author{
Shofiyuddin Najih \\ Universitas Stikubank Semarang \\ shofiyuddinnajih@gmail.com
}

\author{
Anwar Mansyur \\ Universitas Stikubank Semarang \\ a.n.mansyur@gmail.com
}

\begin{abstract}
This study aims to determine and analyze the influence of organizational culture and Work-Family Conflict on the Organizational Citizenship Behavior of teachers under the auspices of the Islamic Education Welfare Foundation, Susukan, Cirebon Regency which consists of kindergarten, elementary, junior high, MTs, MA, SMA and SMK. This study uses a survey method using path analysis techniques including: model analysis, hypothesis testing and determining the level of influence. The process of collecting data for teachers of the Islamic Education Welfare Foundation, Susukan, Cirebon Regency used a questionnaire as a research instrument which was distributed to the entire population with the following criteria: 1) Married teachers, 2) Teachers who already had children. With these criteria, 107 samples were collected. Based on the data analysis that has been done, it can be concluded that first, Organizational Culture has a positive and significant effect on Organizational Citizenship Behavior, secondly, Work-Family Conflict has a positive but not significant effect on Organizational Citizenship Behavior.
\end{abstract}

Keyword Organizational Culture, Work-Family Conflict, Organizational Citizenship Behavior

\section{PENDAHULUAN}

Peningkatan mutu pendidikan disuatu negara dapat dilihat dari peningkatan pertisipasi pendidikan serta semakin banyaknya tenaga ahli yang dihasilkan melalui sistem pendidikan yang diterapkan. Salah satu faktor penting pembangunan nasional dalam rangka meningkatkan kualitas sumber daya manusia yaitu dengan cara meningkatkan mutu pendidikan. Pendidikan merupakan ujung tombak dalam menciptakan sumber daya manusia yang berdaya saing global.

Menurut pasal 3 undang-undang No. 20 tahun 2003 tentang sitem pendidikan nasional, menjelaskan fungsi pendidikan nasional untuk mengembangkan kemampuan dan membentuk watak serta peradaban bangsa yang bermartabat dalam rangka mencerdaskan kehidupan bangsa, bertujuan untuk berkembangnya potensi peserta didik agar menjadi manusia yang beriman dan bertakwa kepada Tuhan Yang Maha Esa, 
berakhlak mulia, sehat, berilmu, cakap, kreatif, mandiri, dan menjadi warga negara yang demokratis serta bertanggung jawab. Berdasarkan penjelasan tersebut terdapat tiga komponen yang paling esensial dalam sistem pendidikan nasional yaitu peserta didik, guru atau pendidik serta kurikulum yang mengatur proses pendidikan. Peran seorang guru dalam menajalankan proses pembelajaran sangatlah kompleks, seorang guru bukan hanya berperan untuk membuat suasana dan proses pembelajaran yang menyenangkan bagi peserta didik. Tetapi guru juga harus mampu berperan sebagai motivator, inspirator, pelatih, inovator, penasihat, pembangun kreativitas dan juga berperan sebagai evaluator. Melakukan peran sebagai pendidik bukanlah suatu yang gampang, dia harus mempunyai kemauan dan kemampuan yang tinggi serta sikap peduli seorang pendidik untuk melaksanakan tugasnya lebih dari yang tertera dalam tugasnya disebuah organisasi pendidikan.

Peran kompleks seorang guru membuat guru sangat membutuhkan perilaku ekstra dalam menjalankan tugas dan perannya. Organizational Citizenship Behavior (OCB) didefinisikan sebagai "perilaku individu yang bebas, tidak secara langsung atau eksplisit diakui oleh sistem penghargaan formal, dan secara agregat mempromosikan fungsi efektif organisasi" (Organ, 1988, dalam Sondeng \& Husain, 2020). Berdasarkan definisi tersebut bisa kita maknai bahwa OCB merupakan sikap bebas atau sukarela dalam membantu rekan kerja yang mengalami keseulitan. Walapun OCB tidak diakui oleh sistem penghargaan formal tetapi OCB sangat membantu jalannnya organisasi dalam meraih tujuan yang telah ditentukan.

Salah satu faktor yang mempengaruhi sikap kesukarelaan adalah budaya organisasi. Budaya organisasi adalah suatu sistem bersama dari tindakan, nilai, dan keyakinan yang berkembang dalam suatu organisasi dan menjadi keyakinan yang ada dalam perilaku anggota organisasi (Schermerhorn, 2012. Dalam Nurhidayah, et al., 2017). Budaya organisasi harus dikembangkan dengan baik, karena budaya organisasi yang baik akan menimbulkan loyalitas guru terhadap pekerjaan. Beberapa penelitian yang dilakukan oleh Zahreni, et al., 2021; Prasetyo dan Mas'ud, 2021; Kamil dan Rivai, 2021; Saputra dan Supartha, 2019; Agustina dan Kasmirudin, 2017, mennyatakan budaya organisasi berpengaruh positif dan signifikan terhadap Organizational Citizenship Behavior (OCB). Berbeda dengan penelitian yang dilakukan oleh Syarief, et al., 2017, yang menyatakan budaya organisasi tidak berpengaruh terhadap Organizational Citizenship Behavior (OCB).

Yayasan Kesejahteraan Pendidikan Islam (YAKPI) Susukan, Kabupaten Cirebon sebagai oraganisasi yang bergerak dalam bidang pendidikan yang memiliki 7 pendidikan formal (TK, SD, SMP, MTs, MA, SMA, SMK) juga terus berupaya agar guru-guru dapat mendukung dan melaksanakan budaya oraganisasi yang islami serta memiliki prilaku yang positif yang berkontribusi langsung terhadap kualitas kinerja guru serta mampu mencapai tujuan organisasi.

Berdasarkan hasil wawancara terhadap beberapa guru dan kepala sekolah serta observasi awal dari peneliti, terdapat $68 \%$ guru yang kinerjanya dibawah rata-rata dan hanya $32 \%$ guru yang memiliki kinerja yang baik dan sangat baik. Terdapat $37 \%$ guru yang melakukan pekerjaan lebih dari apa yang diminta berdasarkan urain tugasnya. Dengan demikian hanya 37\% guru yang memiliki perilaku kewarganegaraan organisasi dan 63\% guru kurang memiliki perilaku kewarganegaraan organisasi. Selain itu, hampir keseluruan guru yang ada didalam Yayasan Kesejahteraan Pendidikan Islam (YAKPI) mempunya peran ganda. Disatu sisi memiliki peran sebagai suami/istri/ayah/ibu dan disisi 
lain juga berperan sebagai guru yang harus memenuhi kewajibannya. Sehingga sangat besar peluang terjadinya Work-Family conflict.

Konflik kerja-keluarga dapat mempengaruhi Perilaku Kewarganegaraan Organisasi. Menurut Organ 1997, dalam Zuliyanto, et al., 2019, kehidupan setiap individu seringkali mempengaruhi penampilan perilaku dalam Organizational Citizenship Behavior. Beberapa faktor yang mempengaruhi perilaku Organizational Citizenship Behavior antara lain suasana hati dan karakteristik individu yang berasal dari dalam diri individu yang secara tidak langsung berkaitan dengan kehidupan setiap individu. Beberapa penelitian yang dilakukan oleh Arifiani dan Putri, 2021; Jamaluddin, et al., 2019; Paat dan Ratnaningsih, 2018, yang menyatakan Work-Family conflict tidak berpengaruh terhadap Organizational Citizenship Behavior (OCB). Sedangkan penelitian yang dilakukan oleh Aurangzeb, et al., 2017, menemukan hasil Work-Family conflict berpengaruh positif dan signifikan terhadap Organizational Citizenship Behavior (OCB).

\section{LANDASAN TEORI}

\section{Organizational Citizenship Behavior (OCB)}

Organ (1988) dalam Sondeng \& Husain, 2020, mendefinisikan Organizational Citizenship Behavior (OCB) sebagai "perilaku individu yang bebas, tidak secara langsung atau eksplisit diakui oleh sistem penghargaan formal, dan secara agregat mempromosikan fungsi efektif organisasi". OCB merupakan perilaku yang melampaui persyaratan formal pekerjaan dan bermanfaat bagi organisasi (Spector (2000, dalam Nurhidayah et al., 2017).

Indikator utama OCB menurut Organ (2003) dalam Purjani dan Riani (2019) adalah sebagai berikut: 1) Altruisme, yaitu kesediaan untuk membantu ketika rekan kerja membutuhkan bantuan; 2) Conscientiousness, yaitu dedikasi terhadap pekerjaan dan keinginan yang kuat untuk melampaui persyaratan formal organisasi; 3) Sportmanship, yaitu perilaku toleransi yang tinggi terhadap gangguan pekerjaan atau penerimaan pegawai terhadap keadaan yang tidak sesuai dengan kondisi ideal. 4) Courtesy, yaitu perilaku yang mencerminkan karyawan selalu mempertimbangkan apakah keputusan kerja yang dibuatnya mempengaruhi karyawan lain. 5) Civic Virtue, yaitu perilaku pegawai untuk melibatkan diri dalam kegiatan organisasi yang tidak diperlukan dalam pekerjaannya.

\section{Budaya Organisasi}

Budaya organisasi adalah suatu sistem bersama dari tindakan, nilai, dan keyakinan yang berkembang dalam suatu organisasi dan menjadi keyakinan yang ada dalam perilaku anggota organisasi (Schermerhorn, 2012, dalam Nurhidayah, et al., 2017). Sedangkan Vecchio (1995, dalam Suhaya \& Dahlan, 2018) mendefinisikan budaya organisasi sebagai nilai dan norma bersama yang ada dalam suatu organisasi dan diajarkan kepada pekerja yang masuk. Definisi ini menunjukkan bahwa budaya organisasi melibatkan keyakinan dan perasaan bersama, urutan perilaku, dan proses sejarah untuk meneruskan nilai dan norma. Menurut Trang (2013, dalam Ursila 2021), budaya organisasi berfungsi sebagai pengikat seluruh komponen organisasi, menentukan identitas, penyuntikan energi, motivator, dan dapat dijadikan pedoman bagi anggota organisasi yang mampu menjadi alat perekat.

\section{Work-Family Conflict}


Interferensi pekerjaan-rumah dan konflik pekerjaan-keluarga telah didefinisikan sebagai "suatu bentuk konflik antarperan di mana tekanan peran dari domain pekerjaan dan keluarga saling bertentangan sehingga partisipasi dalam satu peran (rumah) dipersulit oleh partisipasi dalam peran lain (pekerjaan)" (Greenhaus, 1985 dalam Aurangzeb et al., 2017). Wharton dan Blair-Loy 2006 (dalam Paat dan Ratnaningsih, 2018) menjelaskan bahwa konflik pekerjaan-keluarga sebagai situasi dengan tuntutan pekerjaan yang bersamaan dengan banyaknya tanggung jawab dalam keluarga. Carikci (2002, dalam Jamaluddin et al., 2019) mendefinisikan WFC sebagai konflik yang terjadi karena adanya ketidakseimbangan dan gangguan yang muncul bersamaan antara peran dalam pekerjaan dan di keluarga dimana seorang individu tidak dapat mengelola berbagai tuntutan yang muncul dan juga merupakan bentuk konflik peran ekstra di mana tuntutan pekerjaan mengganggu tuntutan keluarga dan begitu sebaliknya, misalnya harus menghabiskan waktu di tempat kerja lebih banyak daripada di rumah sehingga menimbulkan konflik dengan suami atau suami mengharuskan istri untuk memenuhi kewajibannya dahulu untuk menyelesaikan pekerjaan rumah tangga sebelum berangkat kerja.

\section{Kerangka Penelitian}

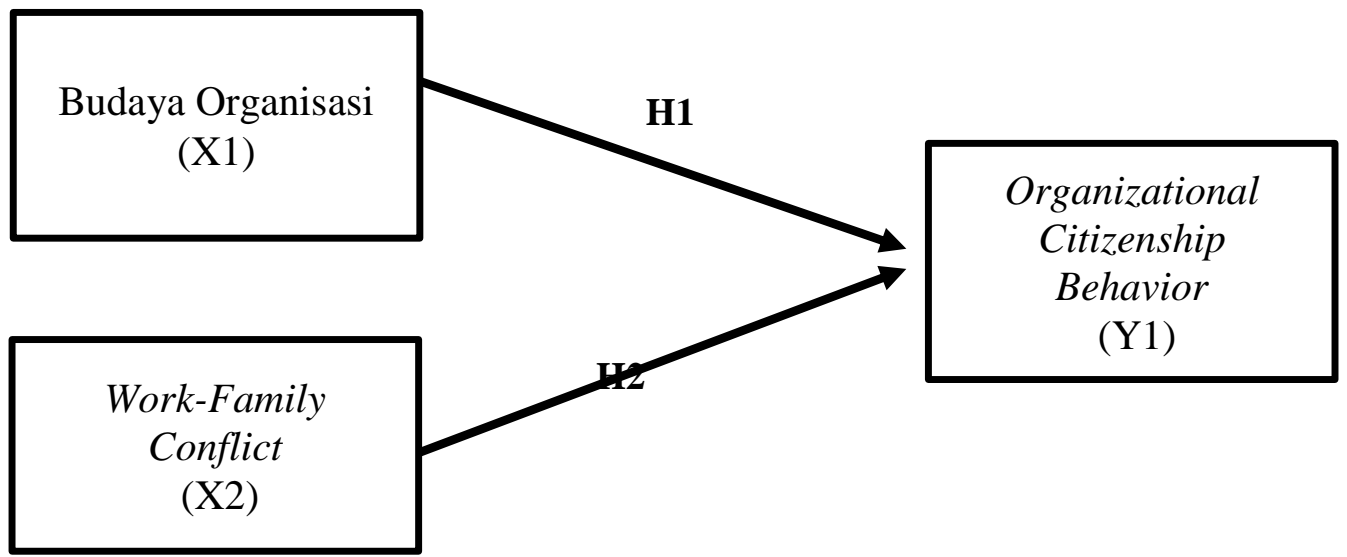

\section{Hubungan antar Variabel Dan Hipotesis}

Budaya Organisasi dan Organizational Citizenship Behavior (OCB)

Faktor budaya (culture) yang dikemukakan oleh Starbuck dan Holloway 2008 (dalam Ramos, 2021) yaitu bahwa karyawan atau staf akan lebih mungkin melakukan tindakan yang melampaui tanggung jawab pekerjaan yang diembannya, jika mereka: (a) puas dengan pekerjaannya, (b) dapat menerima perlakuan sportif dan penuh perhatian dari atasan, (c) percaya bahwa mereka diperlakukan secara adil oleh lembaga atau organisasi.

Budaya organisasi harus dikembangkan dengan baik, karena budaya organisasi yang baik akan menimbulkan loyalitas guru terhadap pekerjaan. Beberapa penelitian yang dilakukan oleh Zahreni, et al., 2021; Prasetyo dan Mas'ud, 2021; Kamil dan Rivai, 2021; Saputra dan Supartha, 2019; Agustina dan Kasmirudin, 2017, mennyatakan budaya organisasi berpengaruh positif dan signifikan terhadap 
Organizational Citizenship Behavior (OCB). Berdasarkan uraian tersebut maka hipotesis dirumuskan sebagi berikut:

H1: Budaya Organisasi berpengaruh positif terhadap Organizational Citizenship Behavior (OCB).

\section{Work-Family Conflict dan Organizational Citizenship Behavior (OCB)}

Menurut Organ 1997, dalam Zuliyanto, et al., 2019, kehidupan setiap individu seringkali mempengaruhi penampilan perilaku dalam Organizational Citizenship Behavior. Beberapa faktor yang mempengaruhi perilaku Organizational Citizenship Behavior antara lain suasana hati dan karakteristik individu yang berasal dari dalam diri individu yang secara tidak langsung berkaitan dengan kehidupan setiap individu. Beberapa penelitian yang dilakukan oleh Arifiani dan Putri, 2021; Jamaluddin, et al., 2019; Paat dan Ratnaningsih, 2018, yang menyatakan Work-Family conflict tidak berpengaruh terhadap Organizational Citizenship Behavior (OCB). Berdasarkan uraian tersebut maka hipotesis dirumuskan sebagi berikut:

H2: Work-Family Conflict berpengaruh negatif terhadap Organizational Citizenship Behavior (OCB).

\section{METODE PENELITIAN}

\section{Jenis Penelitian}

Penelitian ini menggunakan metode penelitian kausal, yaitu melihat hubungan variabel terhadap objek yang diteliti lebih bersifat sebab akibat (causal), sehingga dalam penelitian terdapat variabel bebas dan variabel terikat. Dalam penelitian ini akan diuji pengaruh Budaya Organisasi dan Work-Family conflict terhadap Organizational Citizenship Behavior (OCB) pada guru Yayasan Kesejahteraan Pendidikan Islam (YAKPI) Susukan, Kabupaten Cirebon. Populasi dalam penelitian ini adalah guru Yayasan Kesejahteraan Pendidikan Islam (YAKPI) Susukan, Kabupaten Cirebon. Teknik penentuan sampel dengan menggunakan metode purposive sampling dengan kriteria, 1) Guru yang sudah menikah, 2) Guru yang sudah memiliki anak. Berdasarkan teknik tersebut, diperoleh sampel sebanyak 107 orang.

2. Definisi oeprasional Variabel

\section{1) Budaya Organisasi}

Pola asumsi dasar yang ditemukan, ditemukan, atau dikembangkan oleh kelompok tertentu ketika belajar untuk mengatasi masalah adaptasi eksternal dan integrasi internal yang telah bekerja cukup baik untuk dianggap valid dan, oleh karena itu, untuk diajarkan kepada anggota baru sebagai cara yang benar untuk memahami, berpikir, dan merasakan dalam kaitannya dengan masalah tersebut, Ghosh dan Srivastava (2014)

\section{2) Work-Family Conflict}

Tanggapan/pendapat dari responden terhadap peran lainnya yaitu Work Interference with Family (WIF) dan Family Interference with Work (FIW).

a) Work Interference with Family (WIF)

Merupakan tanggapan/pendapat responden atas dampak atau gangguan yang dirasakan/timbul akibat urusan pekerjaan yang mengganggu urusan keluarga.

b) Family Interference with Work (FIW)

Merupakan tanggapan/pendapat responden atas dampak atau gangguan yang dirasakan/timbul akibat urusan keluarga yang mengganggu urusan pekerjaan. 


\section{3) Organizational Citizenship Behavior (OCB)}

Merupakan tanggapan/pendapat responden tentang perilaku sukarela individu yang tidak berhubungan langsung dengan sistem kompensasi tetapi memberikan kontribusi terhadap efektivitas kerja.

\section{Prosedur Analisis Data}

Dalam penelitian ini digunakan analisis jalur untuk mengetahui pengaruh antar variabel yang diuji menurut model kausal yang terbentuk. Analisis data yang digunakan yaitu Analisis jalur yang meliputi: analisis model, pengujian hipotesis dan penentuan tingkat pengaruh. Dalam proses analisis data, peneliti menggunakan bantuan perangkat lunak Statistical Packages for Social Science (SPSS) versi 21.0.

\section{HASIL PENELITIAN}

Tabel 4.1

Hasil Analisis Jalur

\begin{tabular}{|l|c|c|c|c|c|}
\hline \multirow{2}{*}{} & \multicolumn{2}{|c|}{ Uji Model } & \multicolumn{2}{c|}{$\begin{array}{c}\text { Uji } \\
\text { Hipotesis }\end{array}$} & \multirow{2}{*}{ Ket } \\
\cline { 2 - 5 } & $\begin{array}{c}\text { Adjusted } \\
\text { R } \\
\text { Square }\end{array}$ & Sig. & Beta & Sig. & \\
\cline { 2 - 5 } & .580 & .000 & & .014 & \\
\hline $\begin{array}{l}\text { Budaya Organisasi > } \\
\begin{array}{l}\text { Organizational Citizenship } \\
\text { Behavior (OCB) }\end{array}\end{array}$ & & & .732 & .000 & $\begin{array}{c}\text { H1: } \\
\text { Diterima }\end{array}$ \\
\hline $\begin{array}{l}\text { Work-Family Conflict > } \\
\begin{array}{l}\text { Organizational Citizenship } \\
\text { Behavior (OCB) }\end{array}\end{array}$ & & & .124 & .056 & $\begin{array}{c}\text { H2: } \\
\text { Ditolak }\end{array}$ \\
\hline
\end{tabular}

(Sumber: Hasil olah data primer 2021)

Berdasarkan tabel 4.1 dapat dijelaskan bahwa nilai koefisien adjusted R Square adalah 0,58 yang berarti bahwa variabel Organizational Citizenship Behavior (OCB) dapat dijelaskan oleh variabel Budaya Organisasi dan Work-Family Conflict sebesar 58\% sedangkan sisanya $42 \%$ dijelaskan oleh variabel lain diluar model yang diteliti.

Dari hipotesis pertama budaya organisasi berpengaruh positif terhadap Organizational Citizenship Behavior (OCB), berdasarkan tabel 4.1 diketahui bahwa nilai beta pada variabel Budaya Organisasi terhadap Organizational Citizenship Behavior (OCB) sebesar 0,732 atau 73,2\% dan memiliki nilai signikan sebesar 0,000 $(0,000<$ 0,05), Sehingga dapat diketahui bahwa Budaya Organisasi berpengaruh positif dan signifikann terhadap Organizational Citizenship Behavior (OCB). Hasil penelitian ini mendukung penelitian yang dilakukan oleh Zahreni, et al., 2021; Prasetyo dan Mas'ud, 2021; Kamil dan Rivai, 2021; Saputra dan Supartha, 2019; Agustina dan Kasmirudin, 2017, mennyatakan budaya organisasi berpengaruh positif dan signifikan terhadap Organizational Citizenship Behavior (OCB).

Budaya organisasi yang diterapkan oleh Yayasan Kesejahteraan Pendidikan Islam (YAKPI) Susukan Kabupaten Cirebon cukup baik, hal ini dibuktikan dengan nilai-nilai 
OCB yang sangat baik yang ditunjukkan oleh para guru Yayasan Kesejahteraan Pendidikan Islam (YAKPI). Budaya sangat berpengaruh terhadap perilaku guru, baik dalam bekerja, dalam mengajar, membimbing siwa dan berinteraksi dengan sesame rekan kerja. Dengan demikian apat disimpulkan bahwa ketika budaya organisasi diperkuat, maka OCB akan meningkat.

Hipotesis kedua yang dirumuskan bahwa Work-Family Conflict berpengaruh negatif terhadap Organizational Citizenship Behavior (OCB). Berdasarkan tabel 4.1 diketahui bahwa variabel Work-Family Conflict memiliki pengaruh positif tetapi tidak signifikan terhadap Organizational Citizenship Behavior (OCB) atau bisa dikatakan bahwa hipotetsis kedua Ditolak. Hal itu dibuktikan dengan nilai beta sebesar 0,124 atau 12,4\% dengan nilai signifikansi 0,056 atau > dari 0,05 . Hasil penelitian ini memberikan bukti empiris yang berbeda pada penelitian sebelumnya yang menyatakan sebaliknya, seperti penelitian yang dilakukan oleh Arifiani dan Putri, 2021; Jamaluddin, et al., 2019; Paat dan Ratnaningsih, 2018, yang menyatakan Work-Family conflict tidak berpengaruh terhadap Organizational Citizenship Behavior (OCB).

\section{KESIMPULAN}

Berdasarkan hasil perhitungan dan pengujian hipotesis, penelitian ini dapat disimpulkan, 1) Budaya Organisasi berpengaruh positif dan signifikann terhadap Organizational Citizenship Behavior (OCB). Artinya, penguatan budaya organisasi mengakibatkan peningkatan OCB guru Yayasan Kesejahteraan Pendidikan Islam (YAKPI) Susukan Kabupaten Cirebon. 2) Work-Family Conflict memiliki pengaruh positif tetapi tidak signifikan terhadap Organizational Citizenship Behavior (OCB).

\section{DAFTAR PUSTAKA}

Agustina, D., \& Kasmirudin, (2017). Pengaruh Budaya Dan Komitmen Organisasi Terhadap Organizational Citizenship Behavior (Ocb) Perawat Rumah Sakit Lancang Kuning Pekanbaru (Doctoral dissertation, Riau University).

Arifiani, R. S., \& Putri, V. P. (2021). Pengaruh work family conflict Terhadap organizational citizenship behavior Dimediasi Oleh Komitmen Organisasi. Magisma: Jurnal Ilmiah Ekonomi Dan Bisnis, 9(1), 71-81.

Aurangzeb., Asar, Z., Ilyas, T., \& Bhutto, S. A. (2017). Work family conflict and Organizational Citizenship Behavior in Bank Employees. Industrial Engineering Letters, 7(2). 54-58.

Jamaluddin, M. S. A., Asmony, T., \& Hermanto. (2019). Pengaruh Work-Family Conflict Terhadap Organizational Citizenship Behavior Dengan Mediasi Stres Kerja. JSMBI (Jurnal Sains Manajemen Dan Bisnis Indonesia). 7(9). 189-202.

Kamil, I., \& Rivai, H. A. (2021). Pengaruh Budaya Organisasi dan Keadilan organisasi terhadap Organizational Citizenship Behavior (OCB) dengan Komitmen Organisasi sebagai Variabel Mediasi. (JMK) Jurnal Manajemen dan Kewirausahaan, 6(3), 49-64.

Nurhidayah, A., Nurhattati, \& Matin. (2017). Organizational Culture and Work Environment: Its Effect on Teachers Organizational Citizenship Behavior (OCB). International Journal of Science and Research (IJSR), 6(12), 1517-1521.

Paat, F. D., \& Ratnaningsih, I. Z. (2018). Hubungan Antara Konflik Pekerjaan-Keluarga Dengan Perilaku Kewargaan Organisasi Pada Guru Wanita Sekolah Menengah 
Kejuruan Negeri Di Kecamatan Semarang Timur Kota Semarang. Jurnal Empati. 7(1). 238-246.

Prasetyo, K. D., \& Mas'ud, F. (2021). Analisis Pengaruh Budaya Organisasi, Servant Leadership, \& Komitmen Organisasi Terhadap Organizational Citizenship Behavior (Studi pada Karyawan Hotel Grasia Semarang). Diponegoro Journal of Management, 10(1).

Purjani. N. L. P., \& Riani. I. G. (2019). The Implication of Person-Job Fit and Person Organization Fit on Organizational Citizenship Behavior. International Journal of Science and Research (IJSR), 8(9). 1625-1630.

Ramos, A. (2021). Strategic Leadership and Organizational Culture; Timor-Leste National Police Performance (Empirical Study on the National Police of TimorLeste). International Journal of Science and Research (IJSR), 10(7), 375-391.

Saputra, P. E. W., \& Supartha, I. W. G. (2019). Pengaruh Budaya Organisasi Dan Dukungan Organisasi Terhadap Ocb Dimediasi Oleh Komitmen Organisasional. E-Jurnal Manajemen, 8(12), 7134-7153.

Sondeng, S., \& Husain, Y. S. (2020). The Role of Job Satisfaction towards Organizational Commitment and OCB. International Journal of Science and Research (IJSR), 9(2). 446-449.

Suhaya., \& Dahlan, J. A. (2018). Is The Employee Performance Influenced By Organizational Culture, Work Environment, Work Motivation, And Job Satisfaction?. International Journal of Science and Research (IJSR), 7(12). 10671073.

Syarief, A., Maarif, S., \& Sukmawati, A. (2017). Pengaruh gaya kepemimpinan dan budaya organisasi terhadap komitmen organisasi dan perilaku kewargaan organisasi. Jurnal Manajemen dan Organisasi, 8(3), 173-188.

Undang-Undang Republik Indonesia No. 20 Tahun 2003, Tentang Sistem Pendidikan Nasional.

Ursila. (2021). The Effect of Audit Structure, Organizational Culture, Auditor Professionalism, and Compliance with Auditor Code on Auditor Performance at Public Accountant Firm in Jakarta. International Journal of Science and Research (IJSR), 10(3). 1291-1295.

Zahreni, S,. Simarmata, R., \& Nainggolan, Y. (2021). Pengaruh Budaya Organisasi terhadap Keterikatan Kerja dan Organizational Citizenship Behavior (OCB). Analitika: Jurnal Magister Psikologi UMA, 13(1), 34-43.

Zuliyanto, C., Hermanto, \& Nurmayanti, S. (2019). Influence of Work-Family Conflict Onorganizational Commitment and Organizational Citizenship Behavior (Study at the Manpower and Transmigration Department of West Nusa Tenggara Province). International Journal of Science and Research (IJSR), 8(2), 705-712. 